\title{
Reflections on How to Maintain and Improve Perinatal Care in the Midst of the COVID 19 Pandemic: Let's not Forget Mothers and Newborn Babies!
}

\author{
Augusto Sola ${ }^{1 *}$, Ignacio Pablo Sola ${ }^{2}$, Susana Patricia Rodriguez ${ }^{3}$ and Sergio G Golombek ${ }^{4}$ \\ ${ }^{1}$ Executive Medical Director -Iberoamerican Society of Neonatology (SIBEN), USA \\ ${ }^{2}$ Economist, GANBLIA PLC, Chicago-Dublin \\ ${ }^{3}$ Director Educational \& Research Department, Juan P Garrahan Pediatric Hospital, Buenos Aires, Argentina \\ ${ }^{4}$ Director of Neonatology and Professor of Pediatrics, Joseph M Sanzari Children's Hospital at Hackensack University Medical Center, Hackensack, New Jersey, \\ USA
}

*Corresponding author: Augusto Sola, Executive Medical Director -Iberoamerican

Society of Neonatology (SIBEN), 2244 Newbury, Dr Wellington Fl, USA.

Received Date: April 02, 2020

Published Date: April 08, 2020

\section{Abstract}

Background: The current COVID-19 pandemic has become the most serious public health problem in the world. To respond to COVID-19 pandemia, many countries are using a combination of containment and mitigation activities, with solidarity efforts and resources and funds devoted to its prevention and intensive treatment. To date (April 6, 2020) there are about 1,360,000 confirmed cases and there have been 75,700 deaths reported in 205 countries. However, no serious harm has been reported in infants born to mothers with SARS-CoV-2. Current data suggest that vertical transmission of SARS-CoV-2 is at least uncommon. On the other hand, in many nations overall neonatal mortality rates remain high despite the fact that more than $50 \%$ of the neonatal deaths are reducible.

Objective: Analyze overall population mortality rates in the USA, China and in the 7 Latin American countries with the highest number of births to subsequently compare such data to: a) the mortality due to the COVID-19 pandemic to date, and b) to the current neonatal mortality rates and reducible neonatal mortality in the same regions of the world.

Methods: Data were obtained from several sources, including Federal Centers for Disease Control and Prevention; Johns Hopkins University and Global Health Observatory data repository. Data was compared through tables and descriptive measures. Estimations were performed to assess contribution of mortality due to COVID 19 to the overall mortality and to compare the population mortality and the neonatal mortality due to COVID 19 to neonatal mortality and to reducible neonatal deaths.

Findings: The average number of people dying every day from diverse causes in the 7 Latin American nations combined is 8,930, in the USA is approximately 7,880 and in China 26,000 people die every day. The contribution of the mortality due to COVID 19 to the general mortality to date is about 0,1-0,99\%. The number of persons who have died per day due to COVID 19 is estimated to be 120 in USA, and it was 37 in China, and this is reducible mortality. Neonatal mortality due to COVID-19 has occurred in 1 infant reported to date, and it seems to be extremely rare. In contrast, combining the yearly neonatal deaths from the 7 Latin American nations together with China and the USA, about 399 newborns die every day during one year. Close to 70,000 newborn infants die per year in the 7 Latin American countries with the largest populations. Eliminating neonatal reducible deaths by improving quality of perinatal care, there would be about 35,000 deaths less per year. In China and the USA decreasing reducible mortality could lead to at least 10,000 more infants surviving every year.

Conclusion: Significant efforts and funds are being dedicated to eliminate COVID 19 as a cause of death and they are starting to prove to be effective to eliminate or significantly reduce COVID 19 as a cause of reducible mortality. If reducible neonatal deaths were approached in a similar way, unnecessary and preventable neonatal mortality would cease to exist or be significantly reduced, with drastically less economic costs.

In addition, perinatal and neonatal care should not suffer by this pandemia. Long-term consequences of unnecessary termination of pregnancy, preventing breastfeeding and separation of the mother from the newborn can be very harmful. As pediatricians, neonatologists and neonatal nurses we must not distract our care efforts as this may negatively impact over perinatal well-being. Moreover, recommendations that contradict known evidence cannot and should not be made at this time

Keywords: COVID 19; Perinatal care; Neonatal mortality 


\section{Introduction}

Novel coronavirus infection is a disease caused by severe acute respiratory syndrome coronavirus 2 (SARS-CoV-2) and was named coronavirus disease 2019 (COVID-19) by the World Health Organization on January 7, 2020. The disease spread rapidly throughout China, and has now become a global pandemic. During the first 3 months of 2020, new major epidemic foci of (COVID-19) have been identified and are rapidly expanding in Europe, North America, Asia, and the Middle East, with the first confirmed cases identified more recently in developing African and Latin American nations.

To respond to COVID-19 pandemia, many countries are using a combination of containment and mitigation activities [1], but, today, it is currently difficult to estimate what the impact of this pandemic will be on global health. To date (April 6, 2020) there are about 1,360,000 confirmed cases and there have been 75,700 deaths reported in 205 countries [2]. These numbers will change in the coming weeks and, although projections could be made according to case fatality ratio data, they are still unpredictable.

A comprehensive report published by the Chinese Center for Disease Control and Prevention on 72,314 patients with COVID-19, showed that the case fatality ratio ranged from $2.9 \%$ in Hubei province to $0.4 \%$ in other Chinese provinces [3].

As COVID-19 has spread rapidly across the world, significant solidarity efforts and resources have been devoted to its prevention and intensive treatment of severely affected individuals and never before have so many of the world's researchers focused so urgently on a single topic. The evidence and knowledge of this condition in only starting to be emerging at the present time, but there are still many unknowns and uncertainties.

Despite the sharp increase in the number of COVID-19 infections for the adult population, the incidence and clinical presentations of pediatric COVID-19 infections are varied and differ from those found in adult patients. Current data suggest that vertical transmission of SARS-CoV-2 is at least uncommon and that the virus may not pass to breast milk. Nevertheless, the neonatal population is of course vulnerable to this disease. However, the clinical course of the few infants born to mothers infected with SARS-CoV-2 reported to date varied in the available publications and only a few of them had severe illness and adverse courses that were clearly attributable to COVID 19 [4-9]. On the other hand, in many nations overall neonatal mortality rates are high and have improved too slowly during the last several years, even though it is known that in most places more than $50 \%$ of neonatal deaths are reducible deaths. When this viral pandemia ends, what lessons would we have learnt to act with sensitivity and energy in order to face and improve bad indicators of other stable and well understood pandemics, such as the reducible mortality of newborns in the world due to conditions for which prevention and treatment are well known?

\section{Objective}

This study aimed to analyze overall population mortality rates in the USA, China and in the 7 Latin American countries with the largest populations to subsequently compared such data to: a) the mortality due to the COVID-19 pandemic to date, and b) to the current neonatal mortality rates and reducible neonatal mortality in the same regions of the world.

\section{Methods}

Demographic, epidemiologic and mortality rates data were obtained from several sources, including Federal Centers for Disease Control and Prevention; Johns Hopkins University [10] and Global Health Observatory data repository - WHO [11]. The data gathered included total population and its mortality rates per year, COVID-19 deaths to date (April 6, 2020), live births per year and neonatal mortality rates, for the Latin American countries with the highest number of births, the USA and China. Data was compared through tables and descriptive measures. Estimations were performed to assess contribution of mortality due to COVID-19 to the overall mortality and also to compare mortality due to COVID-19 to neonatal mortality and to reducible neonatal deaths.

\section{Results}

\section{Mortality data for the general population in 7 Latin American countries with the largest populations and in the USA and China}

Relevant aspects of the findings are summarized in Table 1 . The average number of people dying every day from many and diverse causes in the 7 Latin American nations combined is 8,932, in China is 26,000 and in the USA 7,883 people die every day (Table 1). On the other hand, the number of persons who have died per day (on average)due to COVID-19 since the beginning of the pandemia is estimated to be 120 in the USA to date, it was 37 in China and to date is 8 in the 7 Latin American countries (Table 1). The number of average daily deaths is likely to rise in these nations as they entered the pandemia later than China and the USA. Finally, the contribution of COVID-19 related mortality to the general mortality to date can also be derived from data shown in Table 1 . The last column of Table 1 shows deaths attributed to COVID for 3 months (since the time the first case was reported in China). These deaths are related to 3 months data of the overall mortality to obtain the contribution to overall mortality of COVID-19 which is only about $1.5 \%$ of all deaths in the USA, $0.14 \%$ in China and $<0.1 \%$ in the 7 Latin American nations.

\section{Overall neonatal mortality and neonatal deaths due to COVID-19 in 7 Latin American countries with the largest populations and in the USA and China. (Until April 6, 2020)}

The data is summarized in Table 2 . In contrast to the estimated average of daily deaths from diverse causes for the entire population 
and those due to COVID in adults mentioned before, combining the yearly neonatal deaths in the 9 countries mentioned (Table 2) the daily number of neonatal deaths is about 399 during one year.

On the other hand, severe neonatal illness and mortality due to COVID-19 are, fortunately, very rare and infrequent to date. In the report by Zeng [4] on 33 neonates born to mothers with COVID-19, 3 infants had COVID-19 and were ill, and none died. In addition, of the 3 neonates with symptomatic COVID-19, the most seriously ill infant may have been symptomatic from prematurity, asphyxia, and proven bacterial sepsis, rather than SARS-CoV-2 infection [4]. Only one newborn has been reported so far to have died supposedly due to COVID-19 [5]. In this manuscript, there were 10 neonates reported to have serious illness and one died. However, all of them had negative tests for SARS-CoV-2, so the cause of their illness and mortality remains unclear. All these makes impossible to draw definite conclusions on the ultimate cause of death due to COVID-19 in newborn infants.

There were 399 neonatal deaths per day for these regions combined.

\section{Discussion}

Even though the contribution of COVID 19 to the overall population mortality is not high to date (Table 1), this disease is a reducible or preventable cause of mortality. The final contribution of COVID 19 to the general mortality of each region will be better known at the end of this pandemic and will depend on many factors, including the availability of diagnostic tests and access to adequate care. However, it is very unlikely that mortality due to COVID 19 will ever reach similar figures as the neonatal deaths from reducible causes.

Table 1: Population data for the 7 most populated nations in Latin America and for China and the USA (Until April 6, 2020).

\begin{tabular}{|c|c|c|c|c|c|}
\hline Country & Population & $\begin{array}{c}\text { Yearly Deaths n ( } \% 0 \\
\text { Habitants) }\end{array}$ & $\begin{array}{l}\text { Estimated Daily } \\
\text { Deaths \# }\end{array}$ & COVID Test $+(n)$ & $\begin{array}{l}\text { Deaths Due to COVID } \\
\text { (n; } 3 \text { Months)* }\end{array}$ \\
\hline Argentina & $44,000,000$ & $290,400(7 \% 0)$ & 796 & 1451 & 44 \\
\hline Bolivia & $11,000,000$ & $69,300(6.3 \% 0)$ & 190 & 157 & 10 \\
\hline Brazil & $209,000,000$ & $1,400,300(6.7 \% 0)$ & 3,836 & 10,278 & 432 \\
\hline Colombia & $49,700,000$ & $283,290(5.7 \%)$ & 776 & 1406 & 32 \\
\hline Mexico & $129,200,000$ & $801,000(6.2 \%)$ & 2,195 & 1890 & 79 \\
\hline Peru & $31,000,000$ & $192,200(6.2 \%)$ & 527 & 1746 & 73 \\
\hline Venezuela & $32,000,000$ & $224,000(7 \%)$ & 614 & 144 & 3 \\
\hline Total & $505,900,000$ & $3,260,490(6,4 \%)$ & 8,932\# & 17,072 & 673 \\
\hline China & $1,300,000,000$ & $9,490,000(7.3 \%)$ & $26,000 \#$ & 83,005 & 3,340 \\
\hline USA & $330,000,000$ & $2,877,600(8.8 \% 0)$ & 7883\# & $3,67,650$ & 11,000 \\
\hline
\end{tabular}

\section{\# Total yearly deaths/365 days}

* Total reported deaths to date/90 days (3 months of the viral pandemia)

As it should, significant efforts and funds are being dedicated to eliminate COVID 19 as a reducible cause of mortality. For example, the New York Times has recently estimated that the estimated cost over 10 years is about $\$ 170$ billion dollars. As terrible as this viral is, the solidarity responses of nations, dedicating unrelenting effort, time, education and funds, are starting to prove to be effective to eliminate or significantly reduce COVID 19 as a cause of mortality. Undoubtedly, any and every death is a "pain to the heart". pandemic is, and as sad as the loss of human lives due to COVID 19

Table 2: Overall neonatal mortality and neonatal deaths due to COVID-19 for the 7 most populated nations in Latin America, and for China and the USA (Until April 6, 2020).

\begin{tabular}{|c|c|c|c|c|c|}
\hline Country & Population & $\begin{array}{l}\text { Live Births Per Year } \\
\text { (n) }\end{array}$ & $\begin{array}{l}\text { Neonatal Mortality } \\
\text { Rate ( } \% 0 \text { Live Births) }\end{array}$ & $\begin{array}{l}\text { Neonatal Deaths } \\
\text { (n)/12 Months }\end{array}$ & $\begin{array}{l}\text { Neonatal Deaths/ } \\
\text { day\# }\end{array}$ \\
\hline Argentina & $44,000,000$ & 743,000 & $6.4 \%$ & 4,759 & 13 \\
\hline Bolivia & $11,000,000$ & 239,800 & $13 \%$ & 3,120 & 9 \\
\hline Brazil & $209,000,000$ & $2,926,000$ & $10.3 \%$ & 30,138 & 83 \\
\hline Colombia & $49,700,000$ & 730,590 & $8.5 \%$ & 6,210 & 17 \\
\hline Mexico & $129,200,000$ & $2,290,00$ & $5.5 \%$ & 12,580 & 34 \\
\hline Peru & $31,000,000$ & 551,800 & $7.2 \%$ & 3,975 & 11 \\
\hline Venezuela & $32,000,000$ & 588,000 & $14,3 \%$ & 8,420 & 23 \\
\hline TOTAL & $505,900,000$ & $8,067,430$ & $8.6 \%$ & 69,195 & 190 \\
\hline China & $440,000,000$ & $14,650,000$ & $4,3 \%$ & 62,995 & 173 \\
\hline USA & $330,000,000$ & $3,800,000$ & $3.5 \%$ & 13,300 & 36 \\
\hline
\end{tabular}

\#Daily number of neonatal deaths: Total yearly neonatal deaths/365 days 
On the other hand, humane and clinical care of mothers and newborn infants should not suffer due to this pandemia. There are about 8,100,000 babies born each year in the 7 most populated Latin American countries and more than $18,000,000$ in China and the USA. Close to 70,000 newborn infants die per year in the 7 Latin American countries (Table 2). If we estimate reducible deaths as $50 \%$, there would be about 35,000 deaths less per year by improving quality of perinatal care in these nations. In China and the USA, with significantly lower neonatal mortality rates (Table 2), we estimate that decreasing reducible mortality could lead to at least 10,000 more infants surviving every year.

If reducible neonatal deaths were approached in a similar way to the strategies used during this viral pandemia in order to urgently improve quality of perinatal care for all pregnant women and babies, unnecessary and preventable neonatal mortality would cease to exist or be significantly reduced, but to do so would probably require less than $5 \%$ of the funds that have been used for COVID 19 in these past few months. As a recent example of costeffective interventions to decrease neonatal reducible mortality, the Ibero-American Society of Neonatology collaborated with the National Health System in Dominican Republic during 2019, mainly through education efforts. During 2019, 624 less newborns died compared to 2018, with a significant decrease in neonatal mortality rates from $17 \%$ live births to $12 \%$ and a relative risk reduction of $26 \%$. The total cost of the program was 1,100 dollars per each of the 624 babies' lives saved. With a life expectancy of about 70 years, the cost per year of life saved was about 16 dollars, showing that the program was extremely cost effective (Manuscript in press).

In addition to efforts to decrease reducible neonatal mortality, one area of concern that is starting to be recognized from several maternity centers during this pandemia, is that general perinatal and neonatal care may suffer, not only clinically but also in the delivery of compassionate, humane and empathic care. Unnecessary termination of pregnancy, preventing breastfeeding and separation of the mother from the newborn as suggested by some [12] have not been proven to reduce the risk of transmission in other viral illnesses and their short and long-term consequences can be very harmful when applied to the general population. This is serious in any health care system, but particularly so in those systems that are more precarious and that are already showing deficits, like in developing nations. To do these things would be very different to the recommendations made by the Ibero-American Society of Neonatology (SIBEN) [13], and actually would contradict the current recommendations by the US Centers for Disease Control and Prevention (CDC) and World Health Organization (WHO) for the management of COVID-19 [14].

Making recommendations that can affect large number of people requires a sound foundation. In the absence of such a foundation, the medical and academic community should not try to fill the gaps with unsound speculation [14]. SIBEN's recommendations [13] do not contradict those of other organizations and they also encourage to indefatigably maintain empathic and humane quality of maternal and neonatal care in order to avoid potential short- and long-term negative consequences to many mothers and infants as additional untoward effects of this pandemia.

We must continue to care for babies and mothers as we have done, or even better, and not consider that every baby may have COVID 19. As mentioned, this so far has been extremely rare. Consistent with previous studies, the clinical symptoms from 33 neonates with or at risk of COVID-19 were mild and outcomes were favorable [4]. Of the 3 neonates with symptomatic COVID-19, the most seriously ill neonate may have been symptomatic from prematurity [4], asphyxia, and sepsis, rather than SARS-CoV-2 infection. In another report [5], among 9 pregnant women with confirmed 2019-nCoV infection, onset of clinical symptoms occurred before delivery in 4 cases, on the day of delivery in 2 cases, and after delivery in 3 cases. Of the neonates, 6 had serious illness and 1 died. However, all of these neonates had negative results for SARS-CoV-2 in pharyngeal swab specimens collected 1 to 9 days after birth for nucleic acid amplification tests. All these lends support to the current evidence of the low prevalence of COVID 19 in newborns, and makes presently impossible to draw definite conclusions on the ultimate cause of severity of illness or death due to COVID-19 in newborn infants.

As pediatricians, neonatologists and neonatal nurses we must not distract our care efforts as this may negatively impact perinatal well-being. For example, the separation of the mother from the newborn could be harmful. On a regular day, many mothers are scared, stressed, overwhelmed, and exhausted and can easily feel isolated and lonely. These feelings are undoubtedly more prevalent during this pandemia. Such feelings can lead to postpartum depression and anxiety which is not to be taken lightly, as suicide is the second leading cause of death in postpartum women [15]. For these and other reasons, we feel that clear recommendations that contradict known evidence cannot and should not be made at this time. During the significant challenges posed by this viral pandemia, clinical practitioners in perinatal medicine need to act with sensitivity and resolve, without decreasing or modifying care measures for maternal and neonatal conditions for which prevention and treatment are well known, except, of course, if evidence-based recommendations demonstrate that a different approach may be more beneficial.

In addition to the perinatal issues, it is unfortunate that COVID 19 can also interfere with timely, effective and safe care of other conditions, and therefore could increase morbidity and mortality from other causes, by affecting the health system and overwhelming its capacity.

Following the lessons learnt from this pandemia, there is now an opportunity to dedicate joint efforts and funds to significantly improve neonatal survival rates. As Pursley and McCormick recently stated in bending the arc for the extremely low gestational age newborn: "As pediatricians, we must continue to provide strong 
advocacy for policies and programs that support the health of our nation's children, particularly the sickest, smallest, and most vulnerable among them" [16]. This will lead to achieving the rates that have been accomplished for a long time in many nations like Iceland Japan, Cuba, Sweden and others. The mothers and newborns in the world don't have much more time to wait, the time is now!

\section{Acknowledgement}

None.

\section{Conflict of Interest}

No conflict of interest.

\section{References}

1. Bedford J, Enria D, Giesecke J, Heymann DL, Ihekweazu C, et al. (2020) WHO Strategic and Technical Advisory Group for Infectious Hazards. World Health Organization, Lancet, 395(10229): 1015-1018.

2. Coronavirus disease (COVID-19) Situation Dashboard WHO in https:// experience. arcgis.com/experience/

3. Wu Z, McGoogan JM (2020) Characteristics of and important lessons from the coronavirus disease 2019 (COVID-19) outbreak in China: summary of a report of 72314 cases from the Chinese Center for Disease Control and Prevention. JAMA, doi: 10.1001/jama.2020.2648. [Epub ahead of print]

4. Zeng L, Xia S, Yuan W, Yan K, Xiao F, et al. Neonatal Early-Onset Infection With SARS-CoV-2 in 33 Neonates Born to Mothers With COVID-19 in Wuhan, China, JAMA Pediatr, doi: 10.1001/jamapediatrics.2020.0878. [Epub ahead of print]

5. Zhu H, Wang L, Fang C, Peng S, Zhang L, et al. (2020) Clinical analysis of 10 neonates born to mothers with 2019-nCoV pneumonia. Transl Pediatr 9(1): 51-60.

6. Chen H, Guo J, Wang C, Luo F, Yu X, et al. (2020) Clinical characteristics and intrauterine vertical transmission potential of COVID-19 infection in nine pregnant women: a retrospective review of medical records. Lancet 395(10226): 809-815.

7. Lu Q Shi Y (2020) Coronavirus disease (COVID-19) and neonate: what neonatologist need to know. J Med Viro pp. 1-4.

8. Schwartz DA, Graham AL (2020) Potential maternal and infant outcomes from (Wuhan) coronavirus 2019-ncov infecting pregnant women: lessons from SARS, MERS, and other human coronavirus infections. Viruses 12(2): e194.

9. Ma X, Zhu J, Du L (2020) Neonatal management during Coronavirus disease (COVID-19) outbreak: Chinese experiences. Neoreviews 10.1542/neo.21-5-e293.

10. Federal Centers for Disease Control and Prevention; Johns Hopkins University.

11. WHO Global Health Observatory data repository. https://apps.who.int/ gho/data/view.main

12. Favre G, Pomar L, Qi X, Nielsen-Saines K, Musso D, et al. (2020) Guidelines for pregnant women with suspected SARS-CoV-2 infection. Lancet Infect Dis S1473-3099(20)30157-2.

13. Perinatal COVID-19: Recommendations of the Iberoamerican Society of Neonatology. SIBEN shares information for professionals in the neonatal health in relation to the SARS-CoV2 pandemic (Acute Respiratory Syndrome Coronavirus 2 Severe), cause of COVID-19 disease. http:// www.siben.net/images/files/SIBEN_SARS-CoV-2_COVID_19_A_Sola.pdf

14. Schmid MB, Fontijn J, Ochsenbein-Kölble N, Berger C, Bassler D (2020) COVID-19 in pregnant women. Lancet Infect Dis S1473-3099(20)301754.

15. Wisner KL, Sit DK, McShea MC, Rizzo DM, Zoretich RA, et al. (2013) Onset Timing, Thoughts of Self-harm, and Diagnoses in Postpartum Women With Screen-Positive Depression Findings. JAMA Psychiatry 70(5): 490-498.

16. Pursley DM, Mc Cormick MC (2018) Bending the arc for the extremely low gestational age newborn. Pediatr Res 83(4): 751-753. 